\title{
Review Article \\ Effect of PAH Specific Therapy on Pulmonary Hemodynamics and Six-Minute Walk Distance in Portopulmonary Hypertension: A Systematic Review and Meta-Analysis
}

\author{
Muhammad Faisal, ${ }_{1}^{1}$ Furqan Siddiqi, ${ }^{1}$ Ahmad Alkaddour, ${ }^{2}$ \\ Abubakr A. Bajwa, ${ }^{1}$ and Adil Shujaat ${ }^{1}$ \\ ${ }^{1}$ Division of Pulmonary, Critical Care and Sleep Medicine, University of Florida, Jacksonville, FL 32209, USA \\ ${ }^{2}$ Department of Medicine, University of Florida, Jacksonville, FL 32209, USA \\ Correspondence should be addressed to Adil Shujaat; adil.shujaat@jax.ufl.edu
}

Received 19 August 2014; Accepted 19 October 2014; Published 16 November 2014

Academic Editor: Thomas Penzel

Copyright ( $) 2014$ Muhammad Faisal et al. This is an open access article distributed under the Creative Commons Attribution License, which permits unrestricted use, distribution, and reproduction in any medium, provided the original work is properly cited.

\begin{abstract}
Background. Little is known about the effect of pulmonary arterial hypertension (PAH) specific therapy on pulmonary hemodynamics and exercise capacity in patients with portopulmonary hypertension (PoPH) because such patients are usually excluded from randomized clinical trials (RCT) of such therapy. Methods. We searched PUBMED using the terms "(Therapy/Broad (filter)) AND (portopulmonary hypertension)." We included studies that met the following criteria: $\geq 5$ patients, AND PoPH confirmed by right heart catheterization (RHC), AND follow-up RHC data, AND/OR baseline and follow-up 6MWD available. Results. 12 studies met our inclusion criteria. None was a RCT. The baseline mPAP was $48.6 \pm 4.4 \mathrm{mmHg}$, cardiac output $(\mathrm{CO}) 5.6 \pm 0.9 \mathrm{~L} / \mathrm{min}$, and pulmonary vascular resistance (PVR) $668.6 \pm 219.1$ dynes.sec $/ \mathrm{cm}^{5}$. The baseline 6MWD was $348.2 \pm 35.6$ meters. The use of PAH specific therapy improved mPAP by $7.54 \mathrm{mmHg}$ (95\% CI 10.2 to 4.9 ), CO by $1.77 \mathrm{~L} / \mathrm{min}$ (95\% CI 1.1 to 2.4 ), and PVR by 253 dynes.sec/ $\mathrm{cm}^{5}$ (95\% CI 291.4 to 214.6) $(n=135)$ and 6 MWD by 61.8 meters (95\% CI 47.5 to 76$)(n=122)$. Conclusions. The use of PAH specific therapy in PoPH results in significant improvement in both pulmonary hemodynamics and 6MWD.
\end{abstract}

\section{Introduction}

Portopulmonary hypertension (PoPH) refers to pulmonary arterial hypertension (PAH) associated with portal hypertension with or without cirrhosis [1]. The reported incidence ranges from 2 to $9 \%$ [2]. PoPH falls under group I of the WHO classification of pulmonary hypertension as it is histopathologically indistinguishable from idiopathic PAH [3]. It is the third most common cause of PAH after idiopathic $\mathrm{PAH}$ and $\mathrm{PAH}$ associated with connective tissue disease.

Pulmonary arterial hypertension specific therapy has been shown to result in significant improvement in pulmonary hemodynamics and exercise capacity in patients with idiopathic PAH and PAH associated with connective tissue disease [4]. However, little is known about the effectiveness of PAH specific therapy in patients with PoPH since such patients are usually excluded from randomized clinical trials
(RCTs) of such therapy because of overall poor survival as well as concerns about adverse drug effects. The use of PAH specific therapy in patients with $\mathrm{PoPH}$ may, by causing systemic vasodilatation, potentially exacerbate the hyperdynamic circulatory state [5]. There is a concern that epoprostenol may worsen splenomegaly and cause hypersplenism [6, 7], and endothelin receptor antagonists (ERA) may worsen liver function [8].

The effect of PAH specific therapy on pulmonary hemodynamics is particularly important since $\mathrm{PoPH}$ may preclude a patient from undergoing liver transplantation (LT). Mild $\mathrm{PoPH}$, that is mean pulmonary artery pressure (mPAP) < $35 \mathrm{mmHg}$, is associated with negligible perioperative risks, but moderate disease (mPAP $35-50 \mathrm{mmHg}$ ) is associated with a perioperative mortality of $50 \%$, and a mPAP > $50 \mathrm{mmHg}$ is universally fatal [2]. 


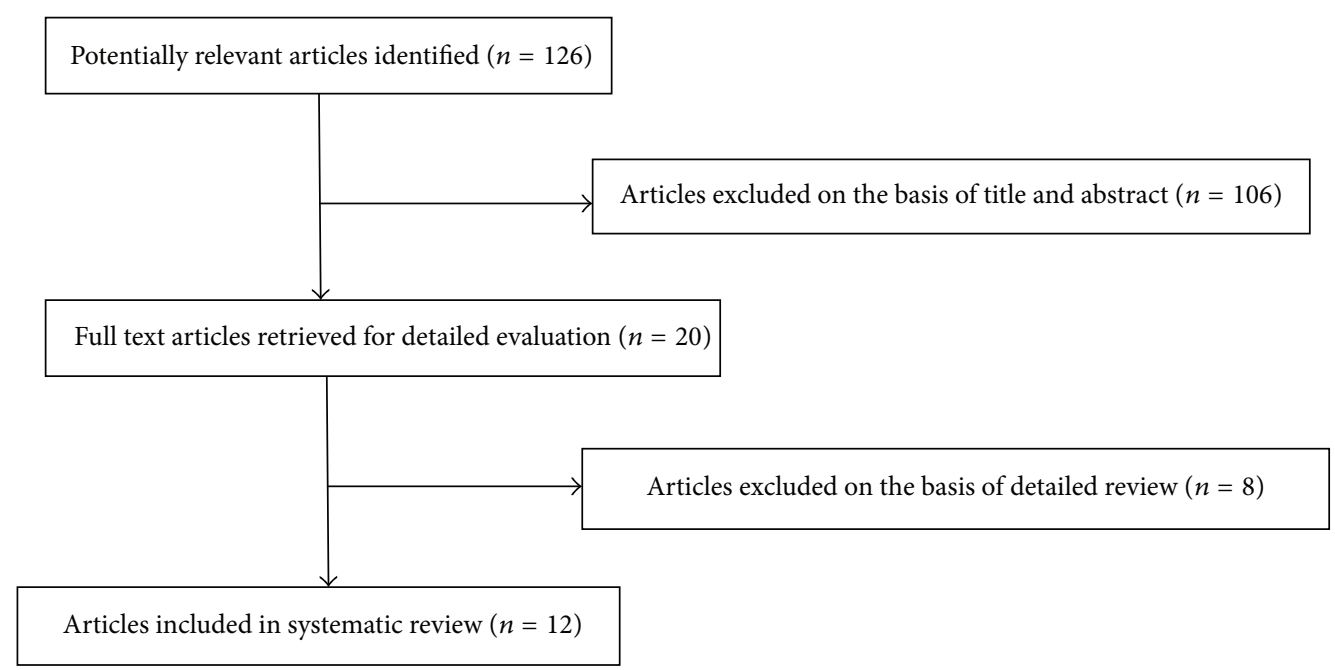

FIGURE 1: Flow diagram of literature search and selection of studies.

We performed a systematic review and meta-analysis of studies of PAH specific therapy in PoPH to determine the effect of such therapy on pulmonary hemodynamics and exercise capacity as measured by six-minute walk distance (6MWD).

\section{Materials and Methods}

2.1. Search Methods. We searched PubMed on September 23, 2013, using the terms "(Therapy/Broad (filter)) AND (portopulmonary hypertension)."

2.2. Inclusion Criteria. We included studies that met the following criteria: $\geq 5$ patients, AND PoPH confirmed by right heart catheterization (RHC), AND follow-up RHC data, AND/OR baseline and follow-up 6MWD data available. PoPH was defined as (i) mPAP > $25 \mathrm{mmHg}$; (ii) pulmonary vascular resistance (PVR) > 240 dynes.sec/ $/ \mathrm{cm}^{5}$; and (iii) pulmonary artery wedge pressure (PAWP) $\leq 15 \mathrm{mmHg}$ or transpulmonary gradient $(\mathrm{mPAP}-\mathrm{PAWP})>12$ [1].

2.3. Study Selection and Data Extraction. Two authors independently evaluated the eligibility of all studies to determine whether they met all inclusion criteria. Disagreements between two authors were resolved with discussion. The main data extracted from the studies included the following: (1) first author; (2) year of publication; (3) country; (4) study design; (5) number of patients treated with $\mathrm{PAH}$ specific therapy; (6) age; (7) sex; (8) cause of portal hypertension; (9) baseline pulmonary hemodynamic data; (10) followup pulmonary hemodynamic data; (11) baseline 6MWD; (12) follow-up 6MWD; (13) PAH specific drugs used; (14) duration of therapy; (15) data on LT; (16) data on the use of beta-blockers; and (17) any adverse drug effects.

2.4. Data Synthesis and Analysis. We used the freeware MetaAnalyst 3.13 and DerSimonian-Laird continuous 1-arm random-effects model to perform the analysis. Pooled effects on pulmonary hemodynamic parameters and 6MWD were presented as weighted mean differences with corresponding 95\% confidence intervals (CIs). Forest plots were created for each outcome. Statistical heterogeneity was assessed using the Cochrane $Q$ statistic (with $P$ values $<0.10$ considered significant). We also calculated $I^{2}$ statistics to estimate the proportion of variation attributable to between-study heterogeneity. In the studies in which the standard deviation (SD) of the mean change of the parameters studied was not provided, we obtained SD from standard error, CI, $t$ values, or $P$ values for differences in means [9].

\section{Results}

A total of 126 articles were retrieved. Twelve studies [10-21] met our inclusion criteria (Figure 1). Three were prospective in design and 9 retrospective. All but one were single arm studies. None was a RCT.

The mean $\pm \mathrm{SD}$ age of the patients was $50.1 \pm 3.6$ years and $52.7 \%$ were males. The underlying cause of portal hypertension in the majority was alcoholic liver disease, chronic hepatitis B or C infection, or both (Table 1). The majority of patients belonged to Child class A. The baseline $\mathrm{mPAP}$ was $48.6 \pm 4.4 \mathrm{mmHg}$, cardiac output (CO) $5.6 \pm$ $0.9 \mathrm{~L} / \mathrm{min}$, and PVR $668.6 \pm 219.1$ dynes $\cdot \mathrm{sec} / \mathrm{cm}^{5}$. The baseline $6 \mathrm{MWD}$ was $348.2 \pm 35.6$ meters. The patients were treated with a variety of PAH specific therapy (Table 2). The duration of follow-up varied from as short as 1 month to as long as 4 years (Table 2).

The use of PAH specific therapy resulted in significant improvements in pulmonary hemodynamics $(n=135)$ and 6MWD $(n=122)$. The mPAP improved by $7.54 \mathrm{mmHg}(95 \%$ CI 10.2 to $\left.4.9 ; I^{2} 77 \%, Q 43.2, P=0.00\right)$, CO by $1.77 \mathrm{~L} / \mathrm{min}$ (95\% CI 1.1 to $2.4 ; I^{2} \quad 78 \%$, Q 36.3, $P=0.00$ ), PVR by 253 dynes $\mathrm{sec} / \mathrm{cm}^{5} \quad$ (95\% CI 291.4 to $214.6 ; I^{2} 1 \%$, Q 10.1, $P=0.43$ ), and $6 \mathrm{MWD}$ by 61.8 meters (95\% CI 47.5 to 76 ; $I^{2} 31 \%, Q 11.6, P=0.17$ ) (Figures 2, 3, 4, and 5). Seven studies $[10,13,14,16-18,20]$ reported data on liver transplantation 
TABLE 1: Underlying causes of portal hypertension in the included studies [10-21].

\begin{tabular}{|c|c|c|c|c|c|c|}
\hline 1st author and year & $N$ & ALD & $\mathrm{HBV}$ or $\mathrm{HCV}$ & Cryptogenic & $\mathrm{ALD}+\mathrm{HCV}$ & Miscellaneous \\
\hline Krowka 1999 & 14 & 1 & 1 & 3 & 3 & $\begin{array}{l}1 \mathrm{HCC}+\mathrm{HCV}, 1 \text { sarcoidosis, } \\
2 \mathrm{PBC}, 1 \text { Budd Chiari, } 1 \mathrm{AIH}\end{array}$ \\
\hline Hoeper 2005 & 11 & 7 & 1 & 0 & 2 & 1 biliary atresia \\
\hline Reichenberger 2006 & 14 & 7 & 3 & & & 3 PBC, 1 Budd Chiari \\
\hline Sussman 2006 & 8 & 4 & 1 & 2 & 1 & \\
\hline Fix 2007 & 35 & 7 & 9 & 3 & 10 & $1 \mathrm{HIV}, 2 \mathrm{HCC}, 2$ PBC, 1 AIH \\
\hline Hoeper 2007 (bosentan) & 18 & 11 & 3 & 1 & 0 & $1 \mathrm{PVT}, 2 \mathrm{AIH}$ \\
\hline Hoeper 2007 (iloprost) & 13 & 6 & 2 & 0 & 0 & 1 biliary duct atresia, $4 \mathrm{AIH}$ \\
\hline Gough and White 2009 & 11 & 4 & 2 & 0 & 4 & $1 \mathrm{ALD}+\mathrm{NASH}$ \\
\hline Hemnes 2009 & 13 & 1 & 8 & 0 & 0 & $1 \mathrm{PBC}$ \\
\hline Melgosa 2010 & 13 & 2 & 7 & 0 & 0 & $\begin{array}{c}1 \text { hemochromatosis, } 2 \mathrm{PBC}, 1 \text { portal vein } \\
\text { thrombosis }\end{array}$ \\
\hline Halank 2011 & 13 & 8 & 1 & 3 & 0 & $1 \mathrm{PBC}$ \\
\hline Hollatz 2012 & 11 & 5 & 1 & 0 & 3 & $1 \mathrm{ALD}+\mathrm{NASH}+\mathrm{PBC}, 1$ biliary atresia \\
\hline Savale 2013 & 34 & 20 & 4 & & 3 & 6 PVT, 1 AIH \\
\hline Total & & $83(40 \%)$ & $43(20 \%)$ & $12(5 \%)$ & $26(12 \%)$ & $41(20 \%)$ \\
\hline
\end{tabular}

ALD: alcoholic liver disease; HBV: hepatitis B; HCV: hepatitis C; HCC: hepatocellular cancer; PBC: primary biliary cirrhosis; AIH: autoimmune hepatitis; HIV: human immunodeficiency virus; PVT: portal vein thrombosis; NASH: nonalcoholic steatohepatitis.

TABLE 2: Regimens of pulmonary arterial hypertension specific therapy used in the included studies [10-21].

\begin{tabular}{|c|c|c|c|c|c|}
\hline 1st author and year & $N$ & $\begin{array}{c}\text { Baseline mPAP in } \\
\text { mm Hg } \\
\text { Mean } \pm \mathrm{SD}\end{array}$ & PAH specific therapy & $\begin{array}{c}\text { Dose } \\
\text { Median (range) unless } \\
\text { otherwise specified }\end{array}$ & $\begin{array}{l}\text { Duration of therapy in } \\
\text { months } \\
\text { Total or median (range) }\end{array}$ \\
\hline Krowka 1999 & 7 & $50 \pm 13.4$ & Epoprostenol & $11(7-48) \mathrm{ng} / \mathrm{kg} / \mathrm{min}$ & $6(3-30)$ \\
\hline Hoeper 2005 & 11 & $53 \pm 9$ & Bosentan & $250 \mathrm{mg} /$ day & 12 \\
\hline Reichenberger 2006 & 12 & $55 \pm 11$ & $\begin{array}{l}\text { Sildenafil } \\
\pm \text { iloprost }\end{array}$ & $\begin{array}{c}150 \mathrm{mg} / \text { day } \\
30 \mathrm{mcg} / \text { day }(n=5)\end{array}$ & 12 \\
\hline Sussman 2006 & 8 & 43 & Epoprostenol & $2-8 \mathrm{ng} / \mathrm{kg} / \mathrm{min}$ & $4.5(2-15)$ \\
\hline Fix 2007 & 14 & $47.9 \pm 8.5$ & Epoprostenol \pm another ${ }^{*}$ & $29(6.5-50.5) \mathrm{ng} / \mathrm{kg} / \mathrm{min}$ & $15.4(6.2-69.8)$ \\
\hline Hoeper 2007 & 13 & $53 \pm 8$ & Bosentan & $250 \mathrm{mg} /$ day & 12 \\
\hline Hoeper 2007 & 11 & $50 \pm 10$ & Iloprost & $30 \mathrm{mcg} /$ day & 12 \\
\hline Gough and White 2009 & 9 & $47.6 \pm 9.9$ & Sildenafil & $150(60-400) \mathrm{mg} /$ day & $5.6(3.2-9.4)$ \\
\hline Hemnes 2009 & 10 & $47.8 \pm 12.1$ & Sildenafil & $60-150 \mathrm{mg} /$ day & 12 \\
\hline Melgosa 2010 & 12 & $55 \pm 10$ & Iloprost & $30 \mathrm{mcg} /$ day & 12 \\
\hline Halank 2011 & 5 & $47 \pm 6$ & Ambrisentan & 5 or $10 \mathrm{mg} /$ day & 12 \\
\hline Hollatz 2012 & 11 & $44.4 \pm 5.5$ & $\begin{array}{c}\text { Sildenafil } \\
+ \text { /or SQ trepostinil }\end{array}$ & $\begin{array}{l}120(60-150) \mathrm{mg} / \mathrm{day} \\
32(19-53) \mathrm{ng} / \mathrm{kg} / \mathrm{min}\end{array}$ & $7(1-48)$ \\
\hline Savale 2013 & 34 & $50 \pm 10$ & Bosentan & $250 \mathrm{mg} /$ day & $4-12$ \\
\hline
\end{tabular}

* Sildenafil (and occasionally bosentan, inhaled iloprost, or subcutaneous treprostinol) was added if the response to epoprostenol was considered by the treating physician to be inadequate, or if side effects greatly limited the ability to achieve an adequate infusion rate of epoprostenol.

(Table 3). Only two studies reported data on the use of betablockers $[12,20]$. No patients were on such therapy in one study [12] and it was discontinued in the other [20].

There were significant adverse drug effects in 3 (11\%) of 28 patients treated with epoprostenol. One of them developed massive splenomegaly and progressive thrombocytopenia $(65,000$ to 6,000 over 18 months of epoprostenol) and died of sepsis following splenic embolization and subsequent splenectomy [10]. The drug was discontinued due to thrombocytopenia, hypotension, headache, and central venous line infections in the other two patients [14]. There was a significant elevation of liver transaminases ( $>3 \mathrm{x}$ the ULN) in $8(11 \%)$ of 72 patients treated with ERAs (bosentan, $n=58$; ambrisentan, $n=14)[15,20]$. The elevation resolved with dose reduction or drug discontinuation. Most of the patients belonged to Child class A cirrhosis and none to class $\mathrm{C}$. There 
Forest plot: $95 \%$ confidence interval

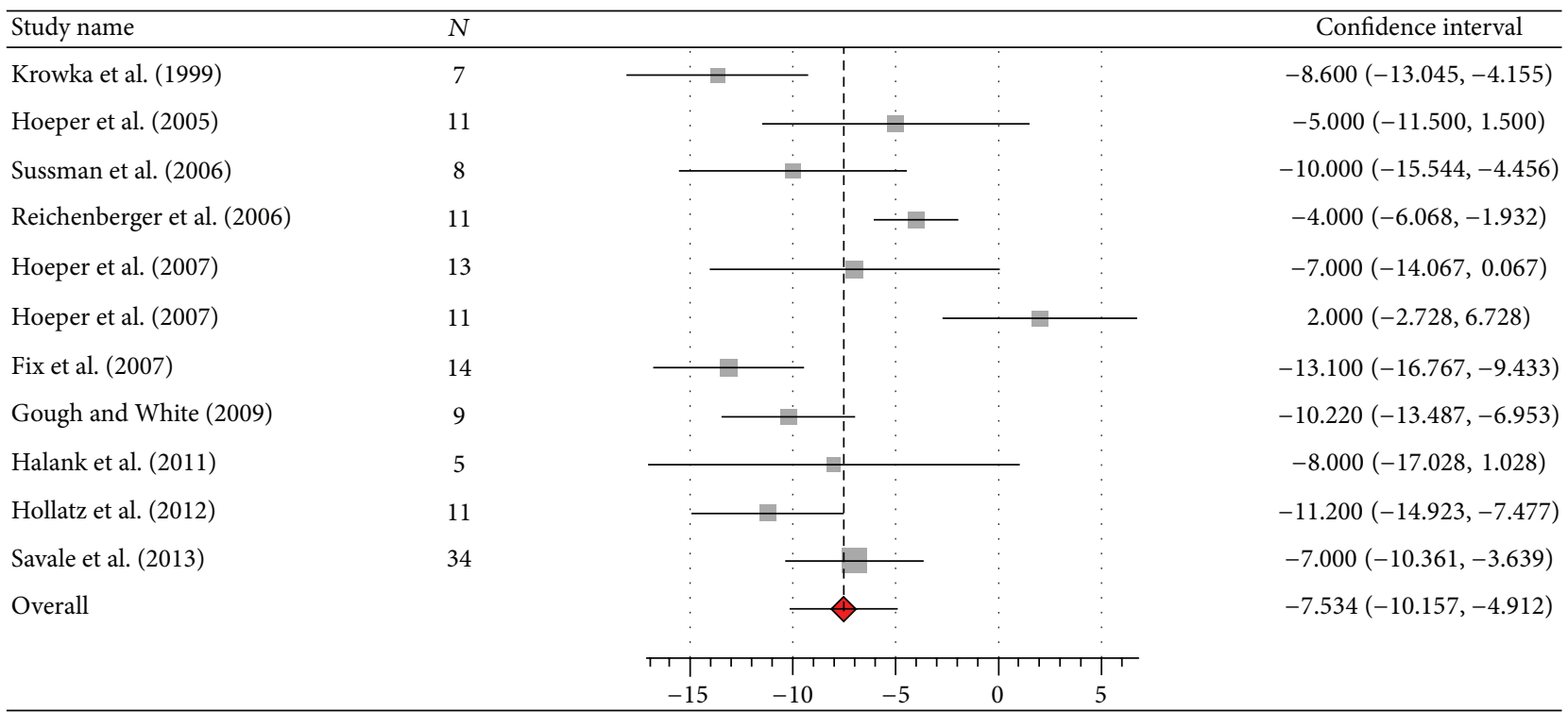

FIGURE 2: Effect of pulmonary arterial hypertension specific therapy on mean pulmonary artery pressure ( $\mathrm{mmHg}$.

Forest plot: 95\% confidence interval

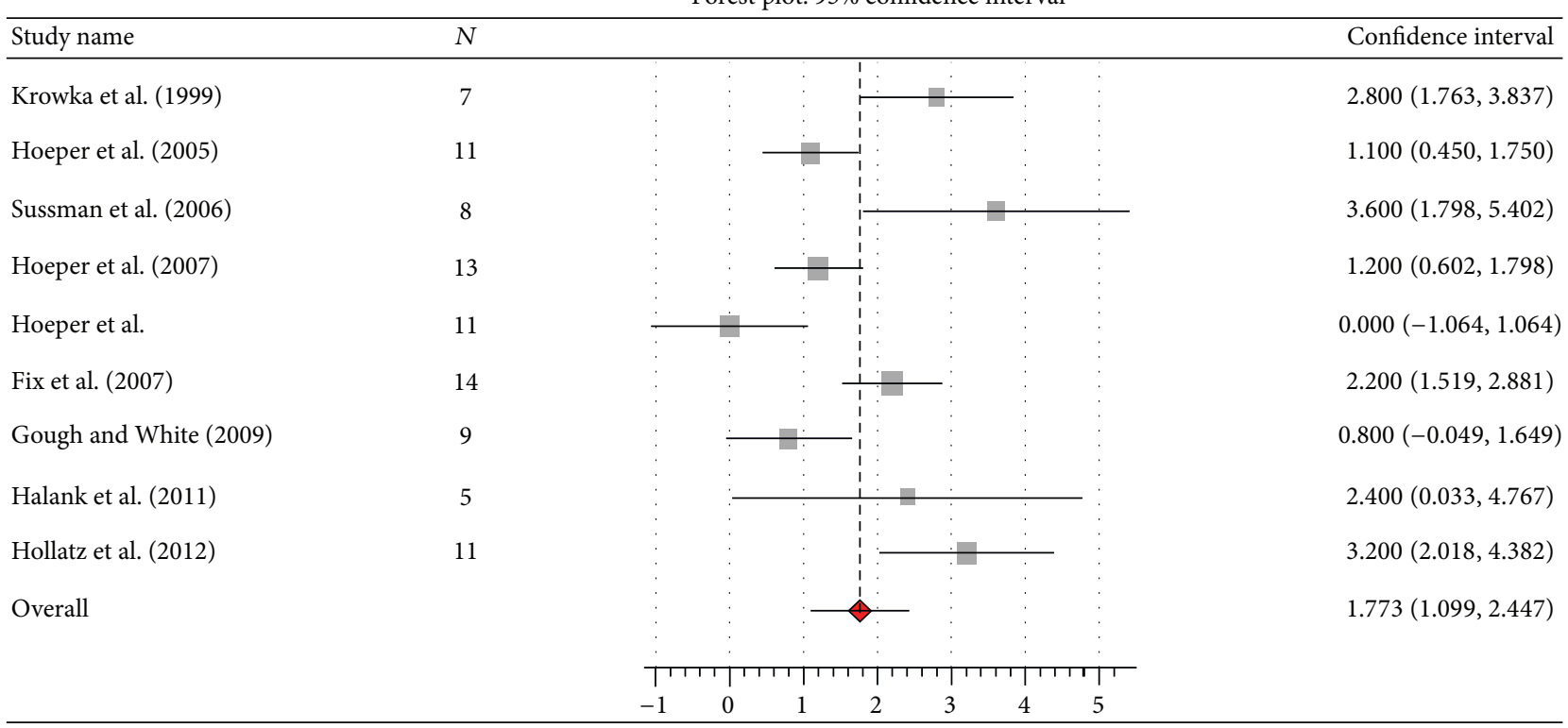

FIGURE 3: Effect of pulmonary arterial hypertension specific therapy on cardiac output (L/min).

were no significant adverse drug effects in patients treated with PDE5I.

\section{Discussion}

This meta-analysis suggests that the use of PAH specific therapy results in significant improvement in pulmonary hemodynamics in patients with PoPH. The mean improvement in mPAP of $7.5 \mathrm{mmHg}$ from a mean baseline mPAP of $48.6 \mathrm{mmHg}$, however, may not be clinically significant since a $\mathrm{mPAP}<35 \mathrm{mmHg}$ is required to safely proceed with LT
[22]. Moreover, there was considerable heterogeneity among the studies. Nevertheless, cases of successful LT were reported in the studies that reported such data (Table 3). Interestingly, the most pronounced mean improvement in MPAP was also seen in these studies: Sussman et al. $(-10 \mathrm{mmHg})$, Fix et al. $(-13 \mathrm{mmHg})$, Gough et al. $(-10 \mathrm{mmHg})$, and Hollatz $(-11 \mathrm{mmHg}$ ) (Figure 2). This appears to be for the following two reasons: the mean baseline mPAP was lower in these studies compared to the others (Table 2), and patients were treated with the intention of bringing the mPAP down to $<35 \mathrm{mmHg}$ to allow LT to be performed safely, a goal which required the use of more than one PAH specific drug 
Forest plot: 95\% confidence interval

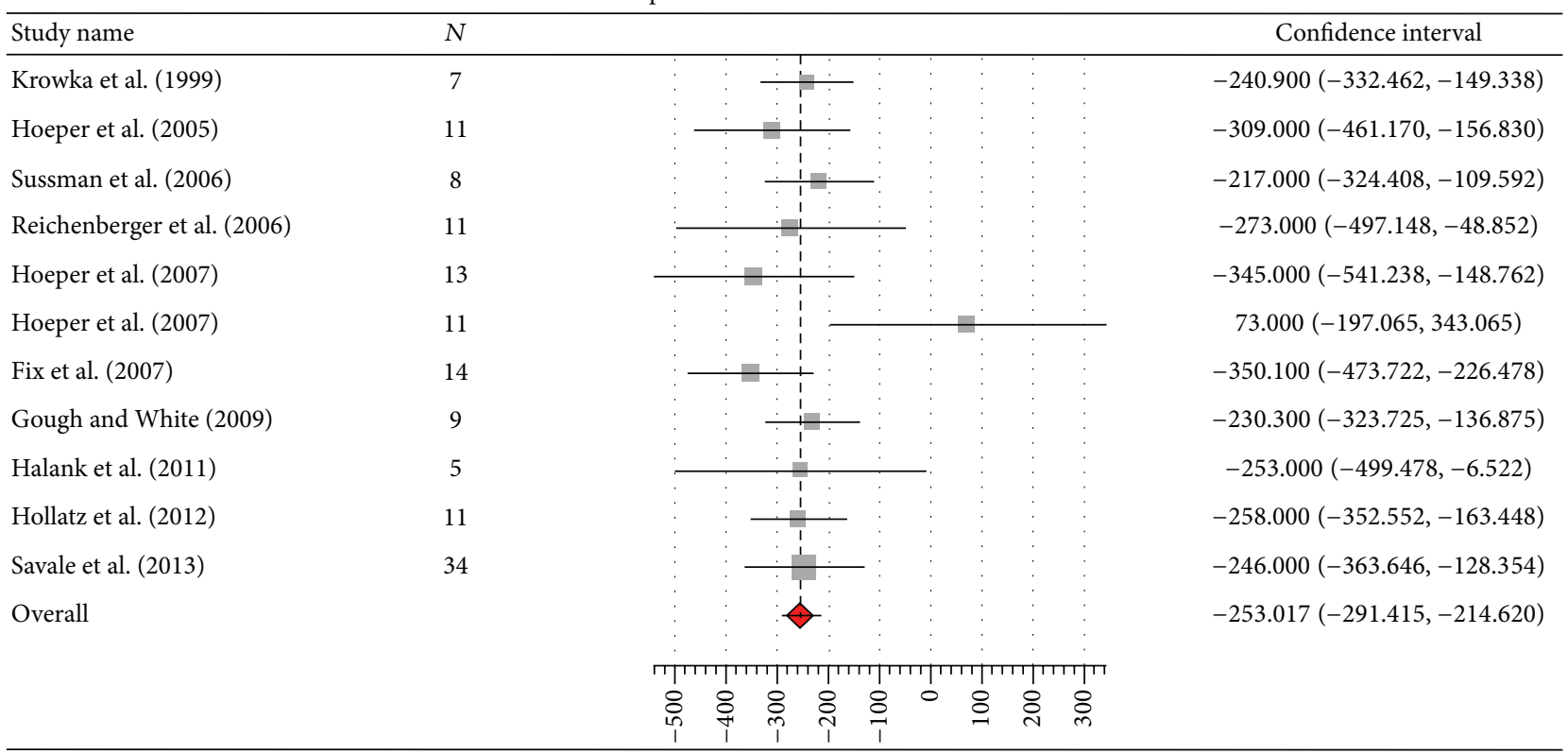

FIGURE 4: Effect of pulmonary arterial hypertension specific therapy on pulmonary vascular resistance $\left(\right.$ dynes $\left.\cdot \mathrm{sec} / \mathrm{cm}^{5}\right)$.

Forest plot: $95 \%$ confidence interval

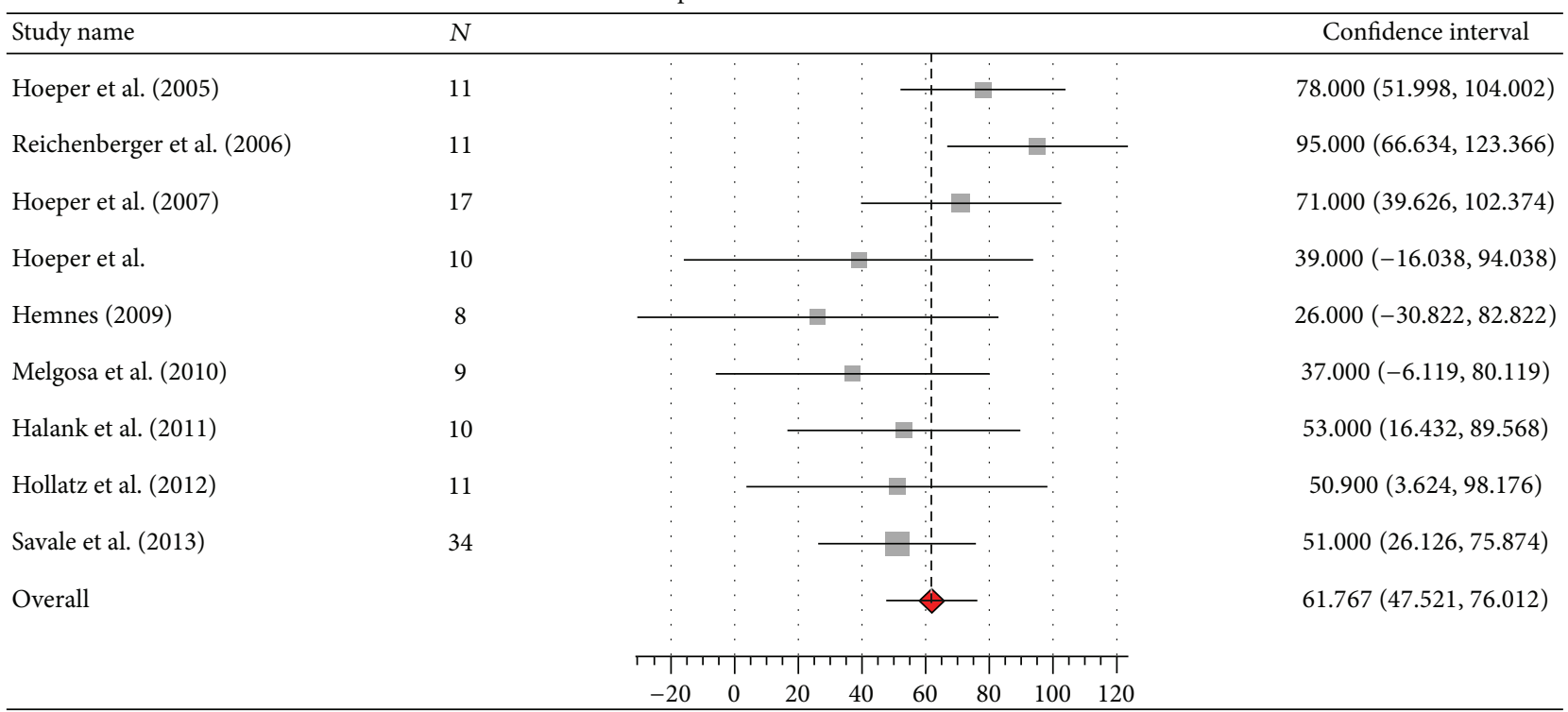

Figure 5: Effect of PAH specific therapy on 6-minute walk distance (meters).

in a number of cases. It may be concluded that the use of a combination of PAH specific drugs may be required in some patients with $\mathrm{PoPH}$ to reduce the mPAP to the level acceptable for LT. However, no particular PAH specific drug or combination of drugs, dosing regimen, or duration of therapy can be suggested since a variety of drugs and dosing regimens were used and duration of therapy varied considerably among the studies. Pulmonary hypertension may rarely persist following $L T$ and warrant continuation of $P A H$ specific therapy $[9,14,20]$.
This meta-analysis also suggests that the use of PAH specific therapy results in significant improvement in 6MWD. The improvement in 6MWD of $61.8 \mathrm{~m}$ is clinically significant, since the minimal clinically important difference in 6MWD in PAH is considered to be $41 \mathrm{~m}$ [23]. Although the possibility of a placebo effect cannot be excluded, the significant improvement in CO suggests the improvement in 6MWD is a result of it rather than a placebo effect. Nevertheless, the interpretation of these results is problematic because whether or not beta-blockers were prescribed or withdrawn for these 
TABLe 3: Data on liver transplantation $[10,13,14,16-18,20]$.

\begin{tabular}{|c|c|c|c|c|c|}
\hline 1st author and year & $\begin{array}{l}N \text { treated with } \\
\text { PAH specific } \\
\text { therapy }\end{array}$ & $N$ eligible for LT & $\begin{array}{l}N \text { who underwent } \\
\text { LT successfully }\end{array}$ & $N$ alive and awaiting LT & $N$ died awaiting LT \\
\hline Krowka 1999 [10] & 7 & 4 & 2 & 2 & \\
\hline Sussman 2006 [13] & 8 & 6 & 4 & & 2 \\
\hline Fix 2007 [14] & 14 & 5 & 2 & & 3 \\
\hline Gough and White 2009 [16] & 9 & 6 & 1 & 2 & 2 \\
\hline Hemnes 2009 [17] & 10 & 3 & 1 & & 1 \\
\hline Melgosa 2010 [18] & 12 & $?$ & 2 & & \\
\hline Hollatz 2012 [20] & 11 & 11 & 11 & & \\
\hline
\end{tabular}

$N$ : number of patients; LT: liver transplantation.

patients was reported in only two studies [12, 20]. Betablockers are often used in patients with portal hypertension to reduce the risk of variceal bleeding. In patients with moderate to severe PoPH (mPAP > $35 \mathrm{mmHg}$ ) they are associated with significant worsening in pulmonary hemodynamics and exercise capacity. Withdrawal of beta-blocker therapy is associated with an increase in $\mathrm{CO}$ and exercise capacity [24].

Adverse drug effects were not uncommon. The rate of significant adverse effects requiring drug discontinuation in patients treated with epoprostenol was $11 \%$. Although splenomegaly and hypersplenism were reported in only one of 14 patients in the series by Krowka et al. [10], a subsequent publication by the same group [6] reported its development in $4(30 \%)$ of 13 patients; however, it is not clear if these were the same patients. Thrombocytopenia was not significant in the series by Fix et al. [14], whereas platelet counts were not reported in the series by Sussman et al. [13]. Nevertheless, splenomegaly with hypersplenism was recently reported in 5 ( $45 \%)$ of 11 patients with PoPH treated with epoprostenol and it was reversible on stopping the drug [7], a phenomenon not reported in the previous study [6] because the drug was not discontinued in any of the patients.

The rate of significant elevation of liver enzymes in patients treated ERAs was $11 \%$. This rate is similar to that reported in those with other forms of $\mathrm{PAH}$ treated with ERAs [25-27]. Such elevation usually develops gradually, remains asymptomatic, and is generally reversible either spontaneously or after dose reduction or discontinuation. It is important to note, however, that none of the patients treated with ERAs in the studies included in this review belonged to Child class $\mathrm{C}$ cirrhosis. There were no significant adverse drug effects in patients treated with PDE5I.

Two studies that were excluded from this meta-analysis because their data could not be pooled are worth mentioning. In one study, the use of PAH specific therapy, mainly epoprostenol, in 16 patients with moderate to severe $\mathrm{PoPH}$ resulted in a significant improvement in mPAP to allow LT to be safely performed in 11 of them [28]. In another study, the use of ambrisentan in 11 patients with moderate to severe $\mathrm{PoPH}$ resulted in significant improvement in mPAP without adverse effect on liver function; however, LT had been performed in only one patient at the time of writing [29].

\section{Conclusions}

The use of PAH specific therapy in PoPH results in significant improvement in both pulmonary hemodynamics and $6 \mathrm{MWD}$. The results of this meta-analysis should, however, be interpreted with caution, since the studies analyzed were uncontrolled case series of a small number of selected patients with moderate to severe PoPH, most of whom belonged to Child class A. A variety of PAH specific drugs were used, in combination in some cases. The duration of follow-up varied considerably among the studies. It is not surprising that there was considerable heterogeneity for MPAP and CO among the studies. Lastly, our search was only limited to PubMed. The use of PAH specific therapy in PoPH needs to be evaluated in RCTs in order to determine the most appropriate treatment regimen in terms of both efficacy and safety.

\section{Disclosure}

The abstract was presented as poster at the annual meeting of American Thoracic Society held in San Diego, CA, in May 2014.

\section{Conflict of Interests}

None of the authors has any conflict of interests with the content of this paper.

\section{References}

[1] R. Rodríguez-Roisin, M. J. Krowka, P. Hervé, and M. B. Fallon, "ERS Task Force Pulmonary-Hepatic Vascular Disorders (PHD) Scientific Committee. Pulmonary-hepatic vascular disorders (PHD)," European Respiratory Journal, vol. 24, no. 5, pp. 861-880, 2004.

[2] M. J. Krowka, "Portopulmonary hypertension," Seminars in Respiratory and Critical Care Medicine, vol. 33, no. 1, pp. 17-25, 2012. 
[3] G. Simonneau, M. A. Gatzoulis, I. Adatia et al., "Updated clinical classification of pulmonary hypertension," Journal of the American College of Cardiology, vol. 62, supplement 25, pp. D34-D41, 2013.

[4] R. J. Barst, J. S. R. Gibbs, H. A. Ghofrani et al., "Updated evidence-based treatment algorithm in pulmonary arterial hypertension," Journal of the American College of Cardiology, vol. 54, supplement 1, pp. S78-S84, 2009.

[5] M. J. Krowka and K. L. Swanson, "How should we treat portopulmonary hypertension?" European Respiratory Journal, vol. 28 , no. 3 , pp. 466-467, 2006.

[6] J. Y. Findlay, D. J. Plevak, M. J. Krowka, E. M. Sack, and M. K. Porayko, "Progressive splenomegaly after epoprostenol therapy in portopulmonary hypertension," Liver Transplantation and Surgery, vol. 5, no. 5, pp. 362-365, 1999.

[7] W. Touma, R. P. Nayak, Z. Hussain, B. R. Bacon, and G. C. Kudva, "Epoprostenol-induced hypersplenism in portopulmonary hypertension," American Journal of the Medical Sciences, vol. 344, no. 5, pp. 345-349, 2012.

[8] C. Eriksson, A. Gustavsson, T. Kronvall, and C. Tysk, "Hepatotoxicity by bosentan in a patient with portopulmonary hypertension: A case-report and review of the literature," Journal of Gastrointestinal and Liver Diseases, vol. 20, no. 1, pp. 77-80, 2011.

[9] http://handbook.cochrane.org/chapter_16/16_1_3_limputing standard_deviations.htm.

[10] M. J. Krowka, R. P. Frantz, M. D. Mcgoon, C. Severson, D. J. Plevak, and R. H. Wiesner, "Improvement in pulmonary hemodynamics during intravenous epoprostenol (prostacyclin): a study of 15 patients with moderate to severe portopulmonary hypertension," Hepatology, vol. 30, no. 3, pp. 641-648, 1999.

[11] M. M. Hoeper, M. Halank, C. Marx et al., "Bosentan therapy for portopulmonary hypertension," European Respiratory Journal, vol. 25, no. 3, pp. 502-508, 2005.

[12] F. Reichenberger, R. Voswinckel, E. Steveling et al., "Sildenafil treatment for portopulmonary hypertension," European Respiratory Journal, vol. 28, no. 3, pp. 563-567, 2006.

[13] N. Sussman, V. Kaza, N. Barshes et al., "Successful liver transplantation following medical management of portopulmonary hypertension: a single-center series," American Journal of Transplantation, vol. 6, no. 9, pp. 2177-2182, 2006.

[14] O. K. Fix, N. M. Bass, T. De Morco, and R. B. Merriman, "Long-term follow-up of portopulmonary hypertension: Effect of treatment with epoprostenol," Liver Transplantation, vol. 13, no. 6, pp. 875-885, 2007.

[15] M. M. Hoeper, H. J. Seyfarth, G. Hoeffken et al., "Experience with inhaled iloprost and bosentan in portopulmonary hypertension," European Respiratory Journal, vol. 30, no. 6, pp. 10961102, 2007.

[16] M. S. Gough and R. J. White, "Sildenafil therapy is associated with improved hemodynamics in liver transplantation candidates with pulmonary arterial hypertension," Liver Transplantation, vol. 15, no. 1, pp. 30-36, 2009.

[17] A. R. Hemnes and I. M. Robbins, "Sildenafil monotherapy in portopulmonary hypertension can facilitate liver transplantation," Liver Transplantation, vol. 15, no. 1, pp. 15-19, 2009.

[18] M. T. Melgosa, G. L. Ricci, J. C. García-Pagan et al., "Acute and long-term effects of inhaled iloprost in portopulmonary hypertension," Liver Transplantation, vol. 16, no. 3, pp. 348-356, 2010.
[19] M. Halank, L. Knudsen, H.-J. Seyfarth et al., "Ambrisentan improves exercise capacity and symptoms in patients with portopulmonary hypertension," Zeitschrift für Gastroenterologie, vol. 49, no. 9, pp. 1258-1262, 2011.

[20] T. J. Hollatz, A. Musat, S. Westphal et al., "Treatment with sildenafil and treprostinil allows successful liver transplantation of patients with moderate to severe portopulmonary hypertension," Liver Transplantation, vol. 18, no. 6, pp. 686-695, 2012.

[21] L. Savale, R. Magnier, J. Le Pavec et al., "Efficacy, safety and pharmacokinetics of bosentan in portopulmonary hypertension," European Respiratory Journal, vol. 41, no. 1, pp. 96-103, 2013.

[22] M. J. Krowka, M. B. Fallon, D. C. Mulligan, and R. G. Gish, "Model for End-Stage Liver disease (MELD) exception for portopulmonary hypertension," Liver Transplantation, vol. 12, no. 12, pp. S114-S116, 2006.

[23] C. Gilbert, M. C. J. Brown, J. C. Cappelleri, M. Carlsson, and S. P. McKenna, "Estimating a minimally important difference in pulmonary arterial hypertension following treatment with sildenafil," Chest, vol. 135, no. 1, pp. 137-142, 2009.

[24] S. Provencher, P. Herve, X. Jais et al., "Deleterious effects of $\beta$ blockers on exercise capacity and hemodynamics in patients with portopulmonary hypertension," Gastroenterology, vol. 130, no. 1, pp. 120-126, 2006.

[25] R. Channick, D. B. Badesch, V. F. Tapson et al., "Effects of the dual endothelin receptor antagonist bosentan in patients with pulmonary hypertension: a placebo-controlled study," The Journal of Heart and Lung Transplantation, vol. 20, pp. 262-263, 2001.

[26] L. J. Rubin, D. B. Badesch, R. J. Barst et al., "Bosentan therapy for pulmonary arterial hypertension," The New England Journal of Medicine, vol. 346, no. 12, pp. 896-903, 2002.

[27] N. Galiè, L. Rubin, M. Hoeper et al., "Treatment of patients with mildly symptomatic pulmonary arterial hypertension with bosentan (EARLY study): a double-blind, randomised controlled trial," The Lancet, vol. 371, no. 9630, pp. 2093-2100, 2008.

[28] M. Ashfaq, S. Chinnakotla, L. Rogers et al., "The impact of treatment of portopulmonary hypertension on survival following liver transplantation," American Journal of Transplantation, vol. 7, no. 5, pp. 1258-1264, 2007.

[29] R. Cartin-Ceba, K. Swanson, V. Iyer, R. H. Wiesner, and M. J. Krowka, "Safety and efficacy of ambrisentan for the treatment of portopulmonary hypertension," Chest, vol.139, no. 1, pp. 109$114,2011$. 


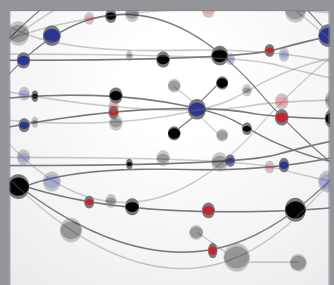

The Scientific World Journal
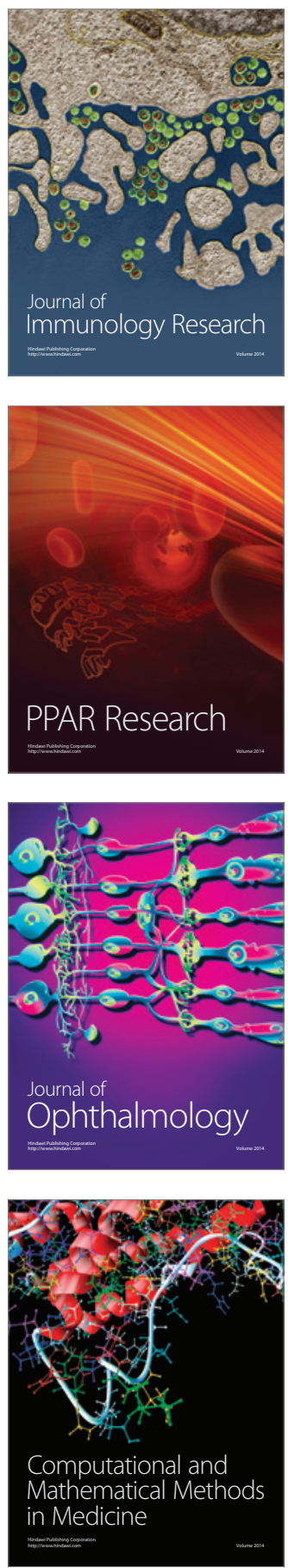

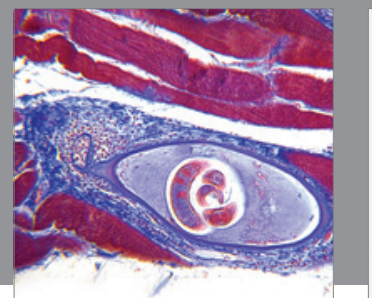

Gastroenterology

Research and Practice
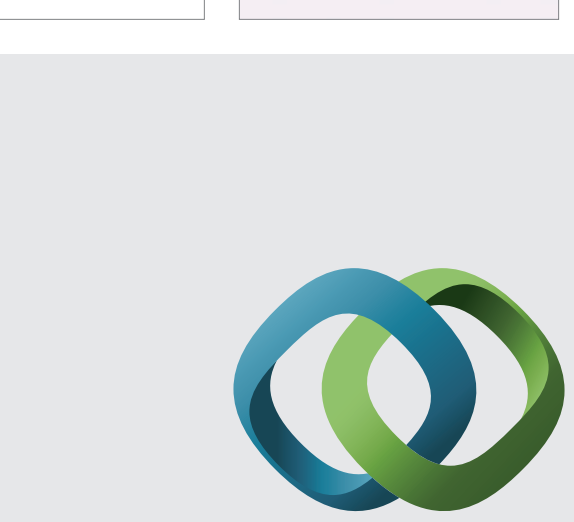

\section{Hindawi}

Submit your manuscripts at

http://www.hindawi.com
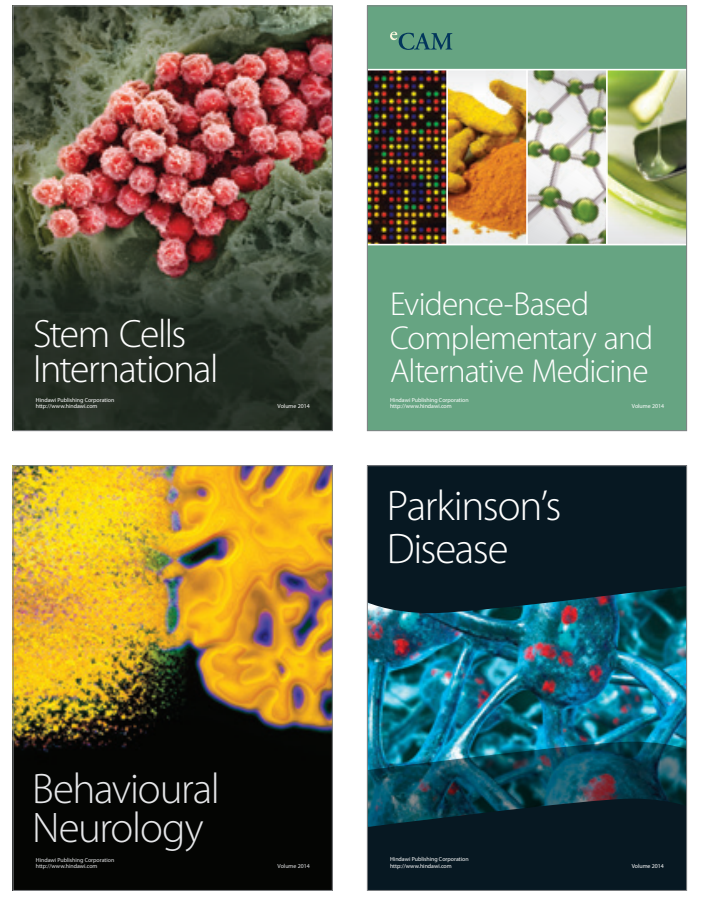
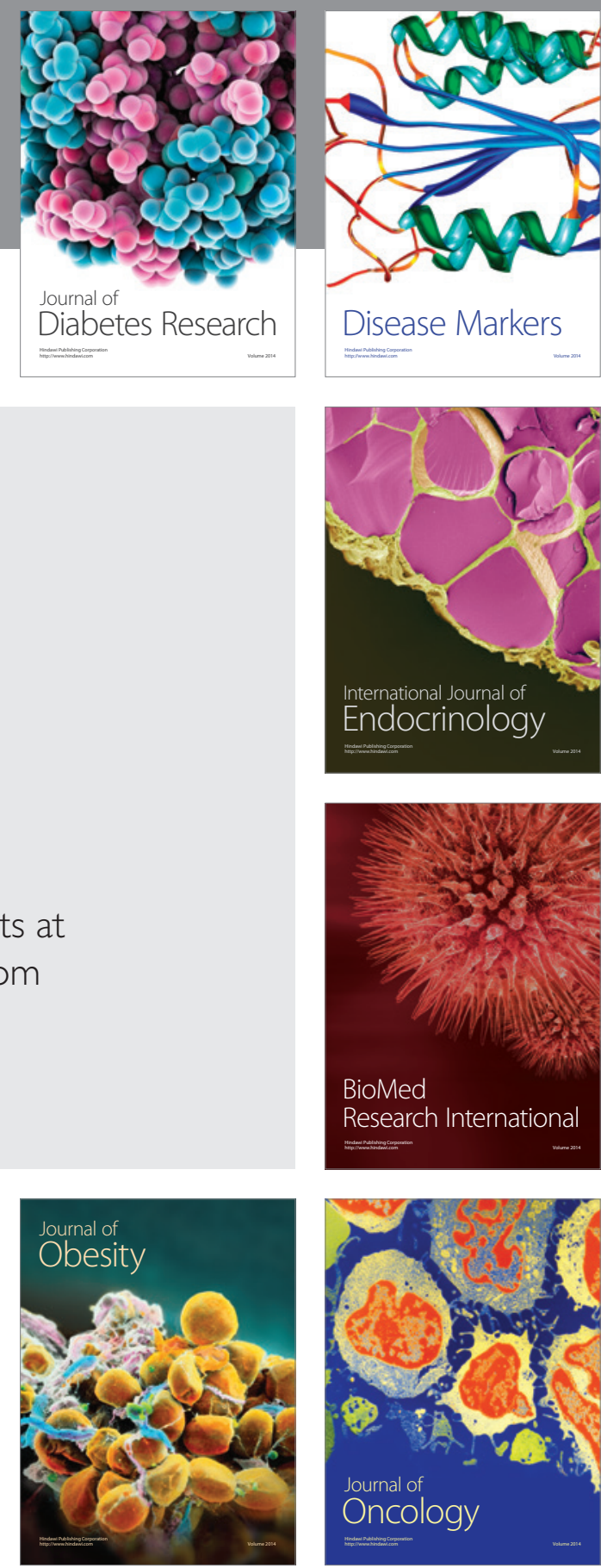

Disease Markers
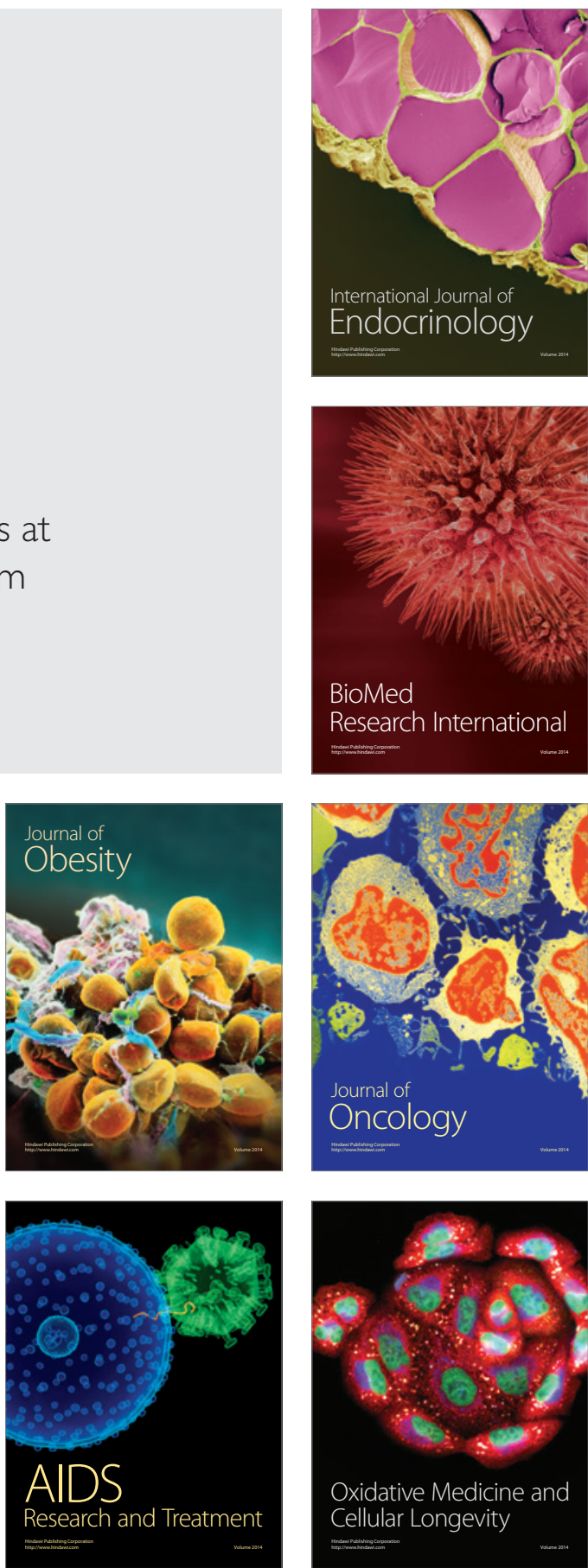